\title{
Transforming Risks into Opportunities in Child Protection Cases: A Case Study with a Multisystemic, In-Home, Strength-Based Model
}

\author{
ANA TEIXEIRA DE MELO and MADALENA ALARCÃO \\ Faculty of Psychology and Education Sciences, University of Coimbra, Portugal
}

\begin{abstract}
Multisystemic, strength-based, in-home, collaborative familycentered programs have been advocated as an efficacious means to belp multichallenged families living in poverty. The Integrated Family Assessment and Intervention Model (IFAIM) was developed in Portugal to assist the child protection system in conducting child protection assessments and in supporting multichallenged families with at-risk children and youth to overcome the risks and guarantee the child's safety. This article describes a single case study evaluating the process and outcome of the implementation of IFAIM with a multichallenged family referred by a child protection agency. The results support IFAIM's efficacy in promoting clinical significant changes in family and parental functioning through supporting the family with a focus on its strengths and key family resilience processes.
\end{abstract}

KEYWORDS child protection, collaborative therapy, family assessment, in-bome therapy, strength-based

\section{INTRODUCTION}

Multichallenged families living in poverty strive to adapt to harsh environments that challenge their abilities and offer them unfavorable resources on which to rely and conditions to develop internal ones (Barnett, 2008; Wadsworth \& Santiago, 2008). They often have to face multiple circumstances

Address correspondence to Ana Teixeira de Melo, Faculty of Psychology and Education Sciences, University of Coimbra, Apartado 1562, ED Devesas, 4400, Vila Nova de Gaia, Portugal. E-mail: anamelopsi@gmail.com 
that, in various areas of their lives, precipitate multiple crises and demand for multiple changes (Minuchin, Colapinto, \& Minuchin, 2007; Sharlin \& Shamai, 2000). Unlike families living in more favorable environments, multichallenged families often lack the opportunities, necessary time, and support to learn, develop, and strengthen the skills and knowledge needed to deal not only with normative challenges but also unexpected negative life events (Melo \& Alarcão, 2011a; Scaramella, Neppl, Ontai, \& Conger, 2008). Child neglect and maltreatment may emerge as messages of the failure of the coupling between the family and its environment and products of ill attempts of the family to reorganize and cope with multiple stressors.

Nevertheless, some families show resilient outcomes and fulfill their functions with adequate levels of competence (Patterson, 2002). Others find ways to recover from distress and some even to strengthen while coping with adversity (Walsh, 2006). Research inspired by family resilience has highlighted several strengths and processes thought to play an important role in minimizing or buffering the impact of risk factors throughout development (Benzies \& Mychasiuk, 2009; Walsh, 2006). This knowledge base has contributed to the development and dissemination of strength-focused approaches to human problems, including in the field of family interventions (Early \& GlenMay, 2000). Many family support programs take advantage of working in the families' home and using multisystemic and ecological frameworks to better address the risks challenging the family's adaptation, enhance protective factors, and help the family change (Boyd-Franklin \& Bry, 2000; Henggeler et al., 2002).

This case study aims to contribute to an understanding of the relevance of family-centered, strengths-based, multisystemic in-home programs and collaboration, assessment, and interventions in cases where a child is at risk and has experienced maltreatment and neglect. It describes a successful implementation of the Integrated Family Assessment and Intervention Model (IFAIM; Melo \& Alarcão, 2011b) with a focus on its process and outcomes regarding a multichallenged family with a child referred due to exposition to multiple risks and neglect.

Specifically, this case study aims to answer the following questions:

1. How does the implementation of IFAIM occur and with what focus?

2. Are the concerns included in the referral addressed during IFAIM's implementation?

3. Does the family change during assessment and/or after intervention? Is that change clinically meaningful? In what dimensions?

4. Did assessment and/or intervention contribute to support the work and meet the needs of the child protection system? How satisfied is the child protection worker with IFAIM's work? Did assessment and/or intervention contribute to meet the needs of the family and child? How satisfied is the family with IFAIM's work?

5. Can the changes be attributed to the implementation of IFAIM? 


\section{METHODS}

\section{Design}

A mixed-methods (qualitative and quantitative), single-case, systematic study design was adopted, because it better fit the descriptive nature of this study and the research questions (Barker, Pistrang, \& Elliot, 2002; Yin, 2009).

\section{Procedure}

The family was referred by a local child protection service to a center for family support and parental counseling, in the north of Portugal, where the first author was implementing IFAIM with the support of professionals from the center's team. For this case, IFAIM's team was composed of the first author (psychologist), who was also the program's developer, and a social educator. The names of the family and its members and other details were disguised to protect the family's confidentiality. Written informed consent was obtained from the family.

\section{INTERVENTION: THE IFAIM}

The IFAIM (Melo \& Alarcão, 2011a) is a manualized assessment and intervention program developed in Portugal to conduct integrative, multisystemic child protection assessments and provide integrative support to families with at-risk, abused, or neglected children. This model complements the work of the child protection system by conducting (1) a risk assessment, focused mainly on risk management and therefore closely linked to (2) a comprehensive assessment (including an assessment of parental capacity, family functioning, and caregivers' characteristics affecting parental capacity as well as the family's social and environmental living conditions), and (3) an assessment of the family's potential for change.

Assessments usually take 3 months to complete and end with a report sent to the referring child protection service (or court). Assessment may lead to a tailor-made intervention plan to support the family in making the necessary changes to ensure the child's protection and well-being and increase the chances of positive development. Both assessment and intervention are conducted from an ecological, systemic framework, with a focus on strengths and family resilience processes. The work is greatly inspired by collaborative (Madsen, 2007), narrative (White, 2007), and solution-focused approaches (Berg \& Kelly, 2000), although contributions from several family and parenting intervention models can be integrated. Following those orientations, assessment often facilitates the family's change even before formalizing support for change. The work is conducted by two professionals (usually a psychologist with a social worker or a social educator) through five stages of implementation: reception (initial interviews), assessment, support 
for change, follow-up, and case closure. The implementation of all stages usually takes place between 1 and 2 years.

\section{Data Collection Procedures}

Quantitative data were collected in three phases: a pretest was collected between the first and second session, an intermediate post-test at the end of the assessment stage, and a final post-test at case closure. Pretest data reported by the professionals was collected retrospectively at the intermediate post-test because in the beginning of the process it was not possible to access all information needed. Satisfaction data were collected at the end of the assessment from the referring professional and from the family both at that time and at case closure. All quantitative data reported by the professionals are obtained through consensus. Both professionals performed their ratings independently and negotiated final scorings by consensus, which were used in this study.

All sessions were audio-recorded, and session summaries were written after each session and organized in a case file, covering the main topics/themes of the sessions, process, and significant outcomes. Therefore, a detailed rich case recording was achieved. The characteristics of the sessions, context, and duration in minutes was registered in an Excel spreadsheet database. At the end of assessment and beginning of support for change, the team interviewed the parents/couple asking their opinion about the changes perceived and the possible contribution of the team's work, family, or other factors contributing to change.

\section{Measures}

Grids For Synthesis of COMPREHENSIVE Assessment In IFAIM

The Grids for Synthesis of Comprehensive Assessment in IFAIM (Melo \& Alarcão, 2011b) are a set of rating scales designed to be filled in by the professionals conducting assessments with multichallenged families with at-risk, abused, or neglected children. They encompass three separate grids, with several subscales, to evaluate different dimensions of parental capacity (PC) (PC_basic care; PC_affective security supervision; PC_stimulation; PC_guidance and limits; PC_physical safety; and PC_protection from others), family functioning (FF) (FF_family functioning; FF_marital relationship), other factors affecting parental capacity (OFAPC) (OFAPC_caregivers' pathological or disturbed functioning; OFAPC_personal contributors of caregivers; and OFAPC_change facilitators), and social and environmental factors (SEF) (SEF_quality of house environment; SEF_domestic management; SEF_employability). The items of each subscale are rated in a five-point Likert scale, according to the instruction of a rating manual. The number of items in each subscale varies between 2 and 7. Ratings of 1 and 2 broadly correspond to situations that can endanger the child and the family and/or 
correspond to poor competence. Ratings of 4 and 5 usually correspond to the existence of strengths and satisfactory levels of competence, likely to contribute for the child's positive development, whereas ratings of 3 generally correspond to risk factors, corresponding to situations where some competences and strengths may be present, although inconsistently and along with some vulnerabilities. These instruments were previously studied and the subscales presented good psychometric properties, namely in terms of the internal consistency (Cronbach alphas ranging from .68 to .96 of its scales and inter-rater agreement; kappa values ranging from .63 to .88) (Melo \& Alarcão, 2011c).

\section{Questionnaire of FAmily STRENGTHS}

The Questionnaire of Family Strengths is a self-report, 29-item questionnaire tested for the Portuguese population (Melo \& Alarcão, 2011c) and designed to assess family resilience processes related to positive family organization, positive family beliefs, positive family support, and management of resources and positive emotions. In this study the global scale was used to provide an index of family strengths. In a previous study the Cronbach alpha of reliability of the global scale was .95 (Melo \& Alarcão, 2011c).

\section{Multidimensional Neglectful Behavior Scale-Parent Report}

The Multidimensional Neglectful Behavior Scale-Parent Report is a self-report instrument designed to evaluate parental neglectful behaviors. In this study a 27-item Portuguese version was used, adapted by Melo and Alarcão (2011d). The items are classified on a five-point Likert scale, which, when formulated in the neglectful direction, separate neglectful behaviors (scores of 0 and 1) from non-neglectful behaviors (scores of 2, 3, or 4). The items formulated in a non-neglectful direction must be reversed and then classified as indicating neglectful behaviors (sores of 0,1 , and 2) or non-neglectful behaviors (scores of 3 and 4). The scores of the scales of this instrument can be calculated to provide a count of neglectful behaviors in different areas, namely emotional and cognitive neglect, physical neglect, supervisory neglect, and neglect by exposure to alcohol and domestic violence. The version used has shown good psychometric properties, with Cronbach alphas for the subscales ranging from .80 to .93 (Melo \& Alarcão, 2011d).

\section{SATISFACTION IFAIM'S SERVICES FORM FOR THE ReFERring Professional AND FAMILY}

The satisfaction forms include items evaluated in a five-point Likert Scale ("not satisfied at all," "little satisfied," "more or less satisfied," "quite satisfied," "very much satisfied") asking the respondent for his or her evaluation of different dimensions of how IFAIM's services were provided 
(e.g., place, schedules) and the satisfaction (for referring professionals) with the outcomes of assessment (e.g., utility of the information produced for decision-making) and support for change, for example, in regard to the family's change and its current capacities (e.g., degree in which the concerns that motivated referral were addressed; family's capacity to deal with future difficulties).

\section{Qualitative Data Analysis Procedure}

All case records were analyzed and audio-recordings were consulted whenever there were doubts about the notes or when they were not sufficiently detailed. The first author content analyzed case records to identify and code all core themes/main areas of change focused during assessment and intervention as well as core activities performed in the session and those suggested to the family as out-of-session activities. This information was organized according to the ecosystemic level of intervention targeted throughout the case, from the individual to larger systems and social and environmental living conditions. The last session was content analyzed for identification of the family's perspectives of core changes and factors contributing to them and, particularly, the role played of IFAIM. Illustrative citations were transcribed.

\section{CASE STUDY}

\section{Case Overview}

The case was completed with success over 13 months during which there were 23 sessions with the family, all but 2 (the first interview and the final assessment interview) in the home. The first two sessions corresponded to the reception stage (initial interviews). Assessment was completed in 3 months ( 9 sessions) and was followed by 7 months of support for change (12 sessions) and 3 months of follow-up ( 3 sessions, including the final session). There were approximately 106 hours of contact with the family and 13 contacts with other professionals from summing approximately 2.5 hours of contacts.

The case was classified as successful according to the following criteria: (1) family preservation was achieved, (2) case was closed in child protection services, and (3) the objectives negotiated with both the child protection services and the families were achieved. At case closure, the family provided the child with minimal safety and well-being conditions.

\section{Initial Information and Referral}

The Green family was composed of the father, Anthony, age 33, the mother, Louise, age 36, and Mary, a 4 year-old girl who had been anonymously 
referred to a local child protection service (in Portugal they are named Comissões de Protecção de Crianças e Jovens (CPCJ) [Commissions of Protection of Children and Youth]). According to CPCJ, the complaint mentioned indicators of child physical neglect; exposure of the child to the father's substance abuse, family conflict, and distress; possible alcohol abuse from the mother; and marital violence. The CPCJ worker investigated the case considering there were indicators of circumstances that could endanger the child and multiple risk factors that needed to be addressed.

At the time of the referral, Anthony was on probation, after leaving jail for crimes related to drug trafficking. He had initiated a methadone drug abuse treatment 3 months before the referral and shortly before the case was open in the CPCJ. The mother earned the national minimum wage, and the father had financial support from the social security system. Their income was barely enough to account for their needs. Little was reported in the referral about the family's strengths or achievements.

\section{Initial Interviews and Case Conceptualization}

Before the initial interview, the team had little information to advance a preliminary hypotheses. The team was interested in knowing more about the family and in exploring its strengths and visions about itself and its future to find where change could be grounded and what factors could facilitate it.

Anthony and Louise were clearly nervous in the first session, but their anxiety seemed to diminish throughout the session. The couple admitted experiencing difficulties but considered that Anthony's participation in the drug abuse treatment program was an important step forward. The team focused on the family's strengths, dreams, purposes, recent positive changes, and solutions as well as on clarifying their role, leaving to the second session more bureaucratic tasks. In the first session, the team also explored the family's visions about current difficulties while positively reframing the problems identified by the CPCJ worker with a focus on solutions. It attempted to understand the family's preferred views of itself, the challenges it had faced throughout its development, and empathize with its difficulties, while highlighting its strengths. This was often repeated and actualized during assessment.

The Greens reported a life filled with multiple challenges, many of which were associated with poverty. Positive and strong affective bonds appeared to be core strengths. Anthony and Louise wanted to continue together and wished to build a strong, happy, united family. Anthony and Louise seemed proud that they were able to "stick together" despite harsh moments. Still, they agreed that their attempts to manage difficulties often turned into conflict and expressed the wish to make things work better between them. Louise exhibited physical signs of tiredness and hopelessness, which were corroborated by her verbal reports. Anthony agreed that it 
"had been too much on her" but was very diligent in repeating how much he wanted to win her trust and support her. He seemed enthusiastic about the possibility of change. Louise was more conservative in her projections into the future, although she verbalized wanting to keep hope high. This was promptly defined as a working objective.

By the end of the first session the team hypothesis about the family's core strengths, including their affection and their ability to hold on to preferred visions of themselves and their future. They also seemed to have had few opportunities to learn how to effectively communicate and support each other. These difficulties were probably salient due to the great stress the family had always been subject to.

These preliminary hypotheses informed the elaboration of the assessment plan, where the exploration and integration of the family's history and strengths became a priority. The team decided to dedicate some sessions to explore factors that could constrain or benefit the quality of the couple's relationship and the role it played in the family's adaptation. Resilience processes related to communication and problem solving and a family's sense of positive identity, shared strength, sense of purpose, cohesion, and positive emotions should be explored hand to hand with the parental capacity issues. The team considered that changes in these processes could facilitate improvement in different areas of the family's life and, eventually, in parental capacity. It seemed there could be some risk factors concerning the parents' ability to dedicate positive attention to the child and to create a reassuring, safe, and stable environment.

\section{Assessment and Support for Change Stage}

In the following sessions and throughout assessment the team explored with the family its history in more depth. Anthony's family of origin was a large family (Figure 1) and, as had Louise's family, faced financial difficulties.

The situation was aggravated when Anthony's father had a severe accident that made it difficult for him to work. All youth had to contribute for the family's income, and Anthony abandoned school at age 13 to work. His mother was too absorbed guaranteeing the family's basic needs and that inattention, along with the reduced capacity of his father to supervise him, were associated, according to Anthony, with his initiation in the use of heroin by age 15. Louise also quitted school early to help her family of origin and started to work when she was 12. She works for the same boss in a local family business for about 10 years and is proud of her working skills and ability to "face all types of work."

The couple started dating when Anthony was 17, but Louise's father did not approve of the relationship. Louise left home in conflict with her father, and the couple's formation was accelerated, as happens with many multichallenged families (Melo, 2011). The couple stated they would have 


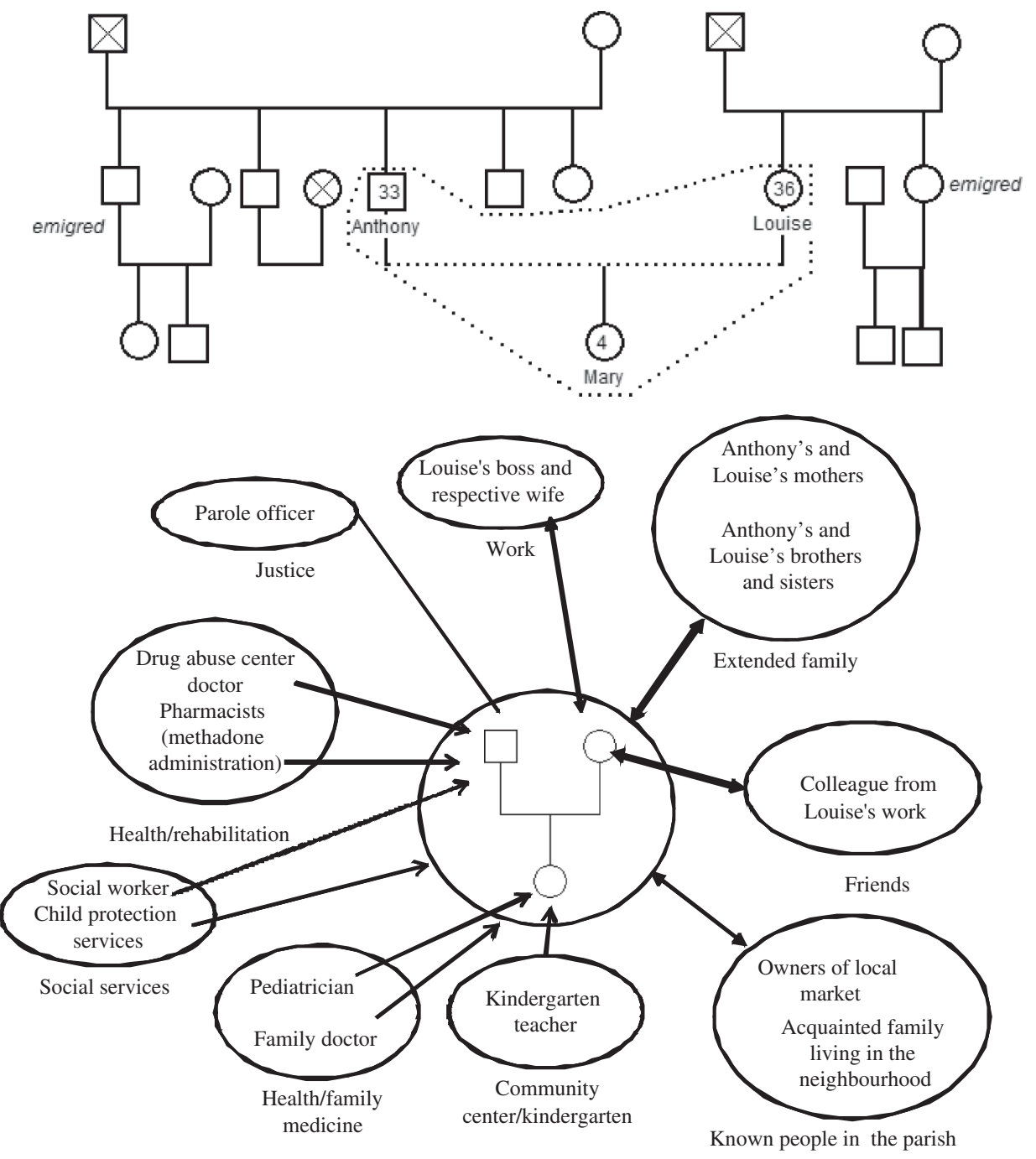

FIGURE 1 The Green's Genogram and Ecomap.

preferred "things to be done in a different way," with more time to plan and prepare their life together. They started their lives sharing a small house with some relatives with whom they experienced conflicts (e.g., intrigues, disturbing triangulations). They had little space of their own and no time to build a solid base for their relationship or to learn how to deal with each other positively.

Two years later, both their fathers died in a short period of time. Anthony's father (who had arranged for the first treatment attempt) was a very important figure to him and was often recruited in the context of remembering conversations (White, 2007) to validate Anthony's change process. Shortly after his death, Anthony was arrested. When Anthony was released 
on parole the couple decided to look for their own place. Anthony was not using drugs at the time, and they decided to have a child. Although the house had poor conditions, they considered it was worth it because they could better support each other and avoid conflicts. A new challenge emerged after the child's birth due to a special health condition that demanded close medical attention and months of staying in the hospital, a period during which Anthony relapsed. After that, the family's situation deteriorated, economical difficulties increased, Anthony's health condition began to be severely impaired, and the couple experienced great distress.

The assessment stage was conducted in respect to IFAIM's orientations and with a collaborative, strengths-based, and solution-based orientation. A family-centered systemic perspective was maintained throughout the process, and meaningful changes were performed before the conclusion of assessment. The team had been mostly focused on family and couple processes, and although parental capacity was assessed, the focus for change, during assessment, was on the former processes.

During assessment it became clear that there was some perturbation in the couple's communication patterns that often escalated into aggression. The couple's relationship seemed to be, simultaneously, the most important factor for family change and the most fragile one. Contrary to the information in the complaint, the team considered there were no indicators of physical neglect. However, parental capacity to provide adequate emotional support, to stimulate the child's development, and to use positive discipline strategies had been constrained by the years of exposure to high levels of stress as well as by the lack of opportunities and material resources. Improvements in the couple's communication facilitated the reorganization of parental roles and increased mutual support.

Table 1 summarizes the core areas of change targeted during both the assessment and support for change stages, although in different degrees in both these stages. The right columns provide examples of activities and strategies used in the sessions as well as activities proposed as homework assignments and materials offered to the family to facilitate the accomplishment of objectives.

At the end of the assessment the team concluded that some problem indicators had been altered and that, although there were still risk factors to address, the child was not endangered. The assessment report was sent, and the case was closed in CPCJ. Nevertheless, the family had shown willingness and capacity to change and benefit from intervention. Therefore, the team proposed to continue to support the family in a support for change stage to help it continue to work and maintain core changes and address risk factors related to parental capacity, to family factors, and the professional inclusion of Anthony's treatment, an aspect that would greatly contribute for relapse prevention. 


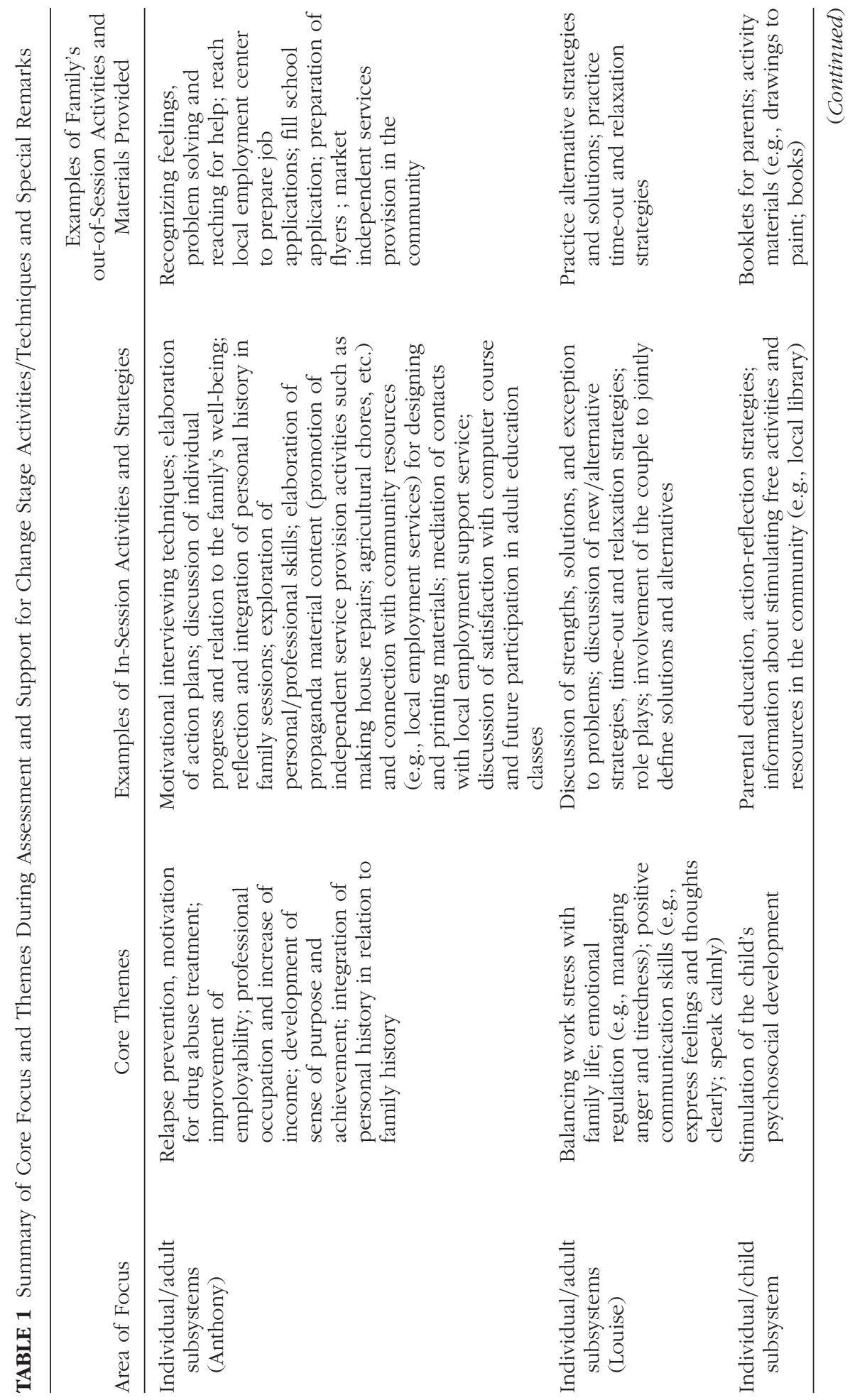




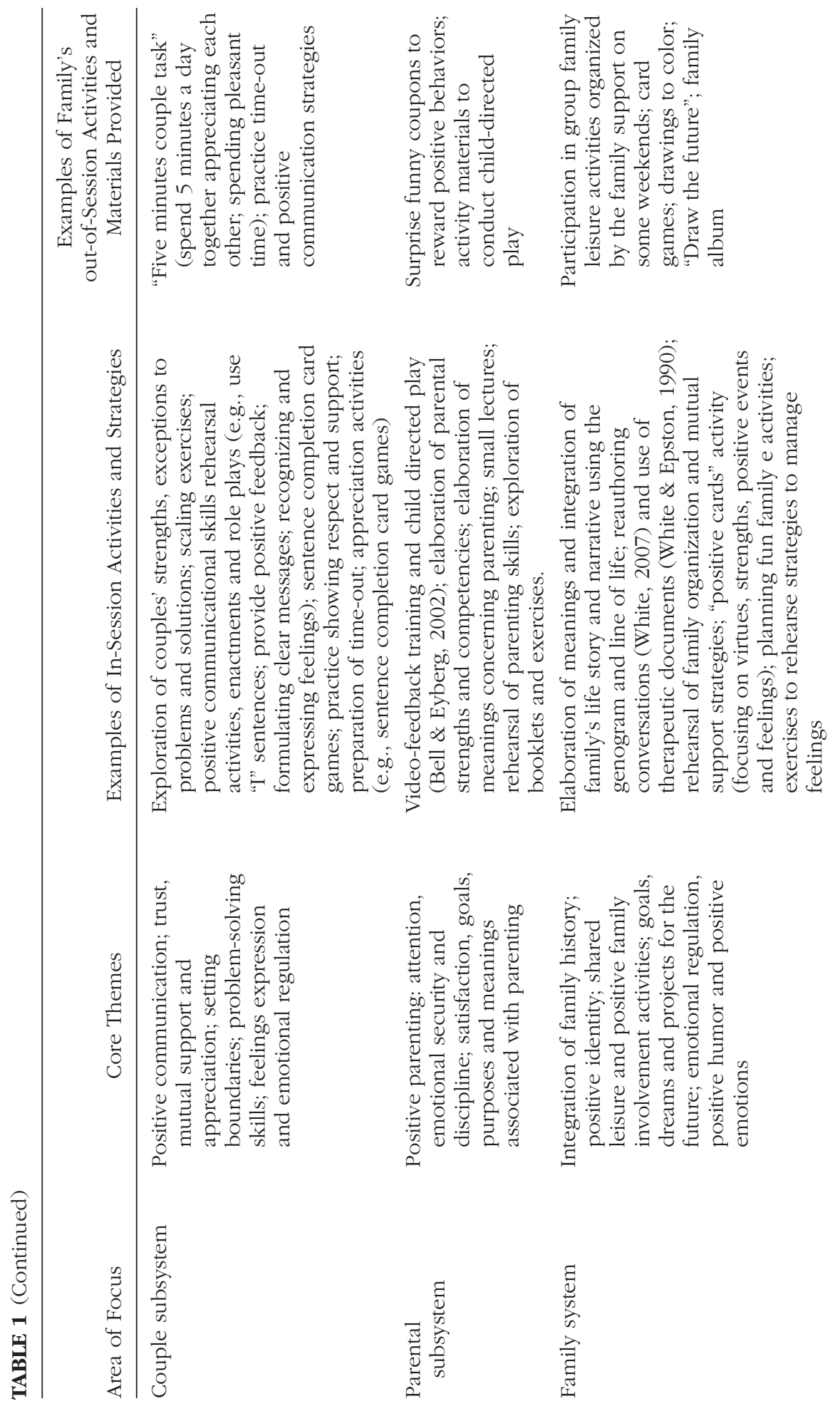



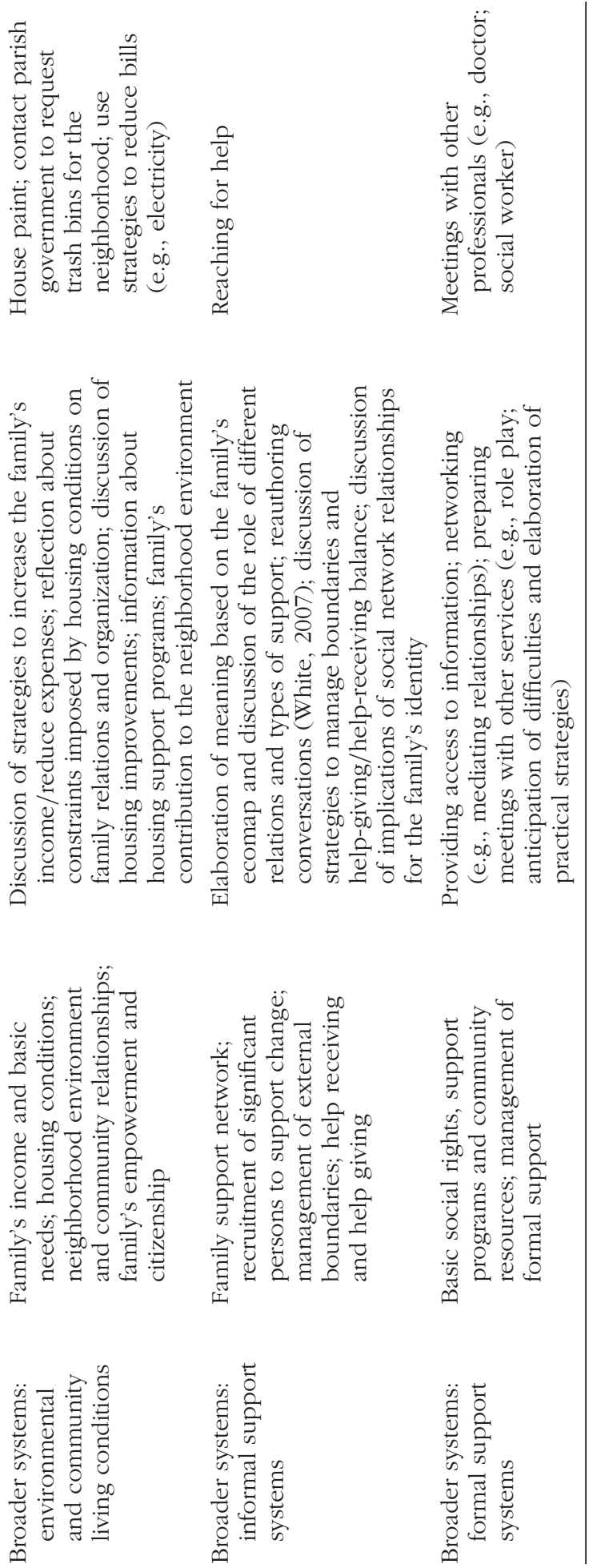
Six months after initiating support for change, Anthony found a job through one of the contacts in the community. By that time he had successfully remained in the drug abuse treatment program for 12 months. A follow-up period was agreed on that would still include parental education contents. Thirteen months after initiating their work, the team and the family agreed significant improvements had been made and it was time for the family to continue on its own. The case was closed, although the family continued to participate in group activities organized by the family center, waiting to participate in group parenting classes, and had offered to help the team in helping other families by sharing their experiences.

On the last session the team produced a therapeutic document focusing on the family's strengths and achievements and the resources they developed to meet future adversity. The document was included in a small book shaped as a green house, taking on the family's drawing, during assessment, of a green house: a house filled with hope for the future. The following sections detail the outcomes of the work with the Greens with IFAIM and some relevant aspects of the qualitative process evaluation.

\section{RESULTS}

To assess the family's changes, we computed the scores of the different variables evaluated at pretest, intermediate pretest (end of the assessment stage), and at the case closure and used graphics to visual inspect for change. The evolution of family and parental variables is illustrated in Figures 2 and 3. As can be seen, there was improvement in practically all variables analyzed, from the pretest to the end of assessment and from this to case closure.

We wanted to inspect the statistical clinical significance of the changes observed. However, due to the lack of information of some normative data information for the instruments used, it was not possible, for most variables, to calculate the statistical significance using the reliable change index (Jacobson \& Truax, 1991). For the same reasons, the criteria for calculating clinical significance varied. In this regard, we generally assumed one of two criteria. First, clinical significance was established when results after intervention were closer to the mean of a functional population than to a clinical population and, accordingly, exceeded the cut-off point provided by the following formula: $\mathrm{C}_{\text {cutoff }}=\left(\mathrm{M}_{0} \cdot \mathrm{SD}_{1}-\mathrm{M}_{1} \cdot \mathrm{SD}_{0}\right) / \mathrm{SD}_{0}+\mathrm{SD}_{1}$, where $\mathrm{M}_{0}$ is the mean of the general population and $\mathrm{M}_{1}$ is the mean of the clinical population and $\mathrm{SD}_{0}$ and $\mathrm{SD}_{1}$ are the corresponding standard deviations (Campbell, 2008; Jacobson \& Truax, 1991). Second, clinical significance was established when the results of the change fell into the normative range of values for a given scale, considering the established and available criteria for the Portuguese population. 

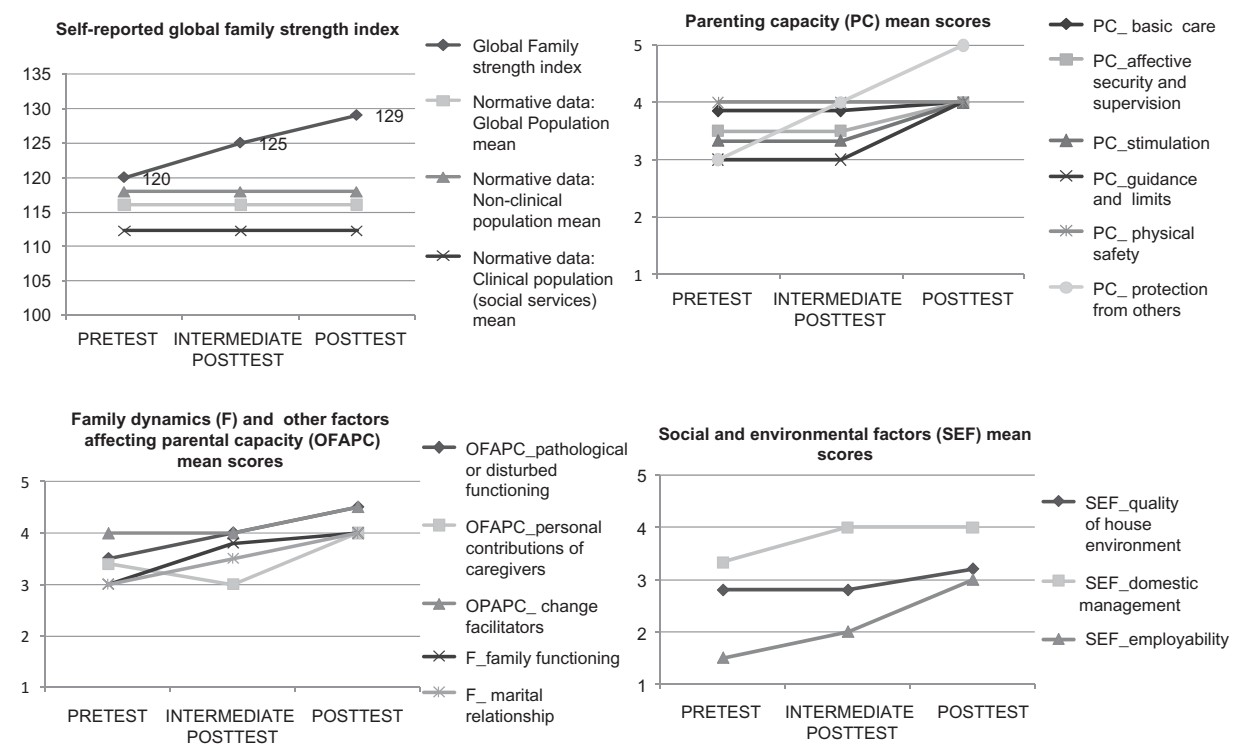

FIGURE 2 Evolution of Family and Parental Variables.

Using the norms described by Melo and Alarcão (2011c), we calculated a cut-off point for the index of family strengths, which yielded a value of 115.52. All the family's scores were superior to this value and to the mean for the global population reported (116.07). Although Figure 2 indicates an increase of the family strength index, the reliable change index calculation for change between the pretest and final posttest was of 1.59 and therefore not statistically significant (inferior to 1.96).

There were increases in the mean scores of most dimensions reported by the team in regard to parenting capacity, family dynamics, other factors affecting parental capacity, and social and environmental living conditions. However, from the pretest to intermediate post-test there was almost no improvement in parental capacity. For that interval most changes were in family and marital functioning and parents' personal factors influencing parental capacity. Available normative data for these variables exist only for a clinical population of social service family users (Melo \& Alarcão, 2011b). These norms report not the mean scores of the variables but the number of danger indicators (scores of 1 and 2) for parenting variables only. The existence of danger indicator was taken as a cut-off point to evaluate the relevance of indicators of danger clinical change. We calculated for each parent and family subscale (except for change facilitators) the number of danger indicators and the number of indicator of risk (scorings of 3). Figure 3 shows the distribution obtained. The absence of danger and risk by the end of the intervention was considered as indicator of the clinical significance of change in family and marital functioning and other factors affecting parental capacity. 



FIGURE 3 Distribution of the Number of Danger and Risk Indicators from Pretest to Intermediate and Final Post-Test.

In regard to the evaluation of neglect, we evaluated the number of self-reported behaviors from pretest to final post-test. At pretest there were two reported neglectful behaviors regarding the child's exposure to alcohol abuse and interparental violence, but no such behavior on the intermediate or final post-test. At the intermediate post-test there was report of one physical and one supervisory neglectful behavior but no neglectful behaviors were counted at the final post-test. In the original version of the instruments the authors considered that the presence of one neglectful behavior classified a case as neglectful. In a Portuguese study (Melo, 2011) with the instrument the presence of only one neglectful behavior distinguished a community from a clinical sample (families using services for at-risk or in-danger children) in regard to emotional-cognitive, physical, and supervisory neglect. The absence of reported neglectful behaviors was considered to be clinically meaningful.

\section{Process Evaluation}

The referring professional considered that IFAIM's met her needs as a child protection worker and that assessment produced meaningful information to facilitate decision making. Both at the end of assessment and at case closure the family was satisfied with the services provided. It considered the team to 
be quite competent and respectful of the family. At case closure, the family was very much satisfied and stronger, closer to its preferred views of itself, and confident in its capacity to deal with future difficulties than before IFAIM.

To evaluate IFAIM's contribution for change, we looked for positive arguments in favor and against linking IFAIM to outcomes and looked for processes contributing to change. For this we relied on contributions of hermeneutic single-case efficacy designs used in individual therapy (Elliot, 2002) to define indicators of positive and negative arguments for IFAIM's efficacy in this case.

\section{Positive and Negative Arguments}

We started to look for some direct evidence of the influence of IFAIM on the family's change. The first positive argument is anchored in the Green's statement of the significance of IFAIM to change:

This team made us much good. I really appreciated it. It relieved my head, I disclosed many things. Gave me much strength to face the problems with my head up ... This family was at the bottom of the well and we could raise our heads with the help of this team. ... These sessions helped us keep hope, gave us courage ... you explained things that helped ... with you we talked a lot about many things [that hurt] and now we don't think about them anymore.

A second argument is anchored in the correspondence between process and outcome. The changes observed in family and marital functioning before changes in parental capacity parallel the main focus during the assessment and support for change stage, namely that family and couple issues were given priority before parenting.

A third argument stands against trivial change because there were changes in persisting family difficulties in the first months of work that corresponded to core themes focused on the sessions:

I am now more patient with my daughter and my husband. I don't fight nor yell as much ... we also collaborate more in regard to taking care of Mary ... we now try to get along and talk to each other to solve things out ... we spend more time together, and do more things together. Before I [Anthony] was never home . . . now we are more focused in our family ... and Mary is happier ... we give her more attention ... she doesn't see us fight anymore.

According to Elliot (2002), at least two sources of evidence should be found to support a therapy-change relationship. These three pieces of evidence confirm that link. 
One could believe the family's high levels of strengths could be responsible for change. However, this can also be a positive indicator of IFAIM's contribution because the existence of these strengths did not seem to be enough for change to happen (there was still need for intervention), although they probably contributed to the family's readiness for it.

The support from the extended family and community could have accounted, at least partially, for the family change. Even though Anthony and Louise stated the relation with extended family was strengthened with Anthony's abstinence and facilitated it ("now we are spend more time with our families and they continue to support us"), it is unlikely to be responsible for the family's change because it preexisted.

Anthony's strong motivation for treatment could account for some changes. However, it is clear that his wife's support and the satisfaction with their relationship contributed to prevent relapse along with the improvement of the family climate ("Now we can I ask for her [Louise's] help when I need and she can do the same with me" ... "[now] we fit better" . . "seeing them happy gives me strength") to which IFAIM probably contributed.

After the assessment, Anthony found opportunities to do some sporadic part-time work, which seemed to be important to help the family sustain hope and engage in the changes and learning they were doing. Nevertheless, some core family changes had been made by then. Anthony's finding a fulltime job was a very significant event that released a lot of stress. However, this happened 10 months after the team initiated their work with the family and shortly before entering follow-up. Also, that the researcher was also one of the team members could have influenced the family reports of change.

\section{DISCUSSION}

This case study described what could be a typical implementation of IFAIM with a family referred by child protection services. It illustrates how a collaborative, family-centered assessment and intervention model, focused on strengths and resilience processes and solution orientated, may be suited to help families who are exposed to multiple risks and have their children's safety and well-being endangered. IFAIM may be especially adequate for those families that present sufficient strengths, willingness, and capacity to change but are nonetheless in need of help to activate their resources and assistance to change and learn. This case study also illustrates how a mandated child protection assessment creates a special opportunity and how keeping a focus on the family can facilitate the activation and expansion of core relational strengths. An integrated, multisystemic intervention avoided the risks of multiple assistance and family dilution (Colapinto, 1995).

Despite the existence of rival explanations to the success of the case, some efficacy can plausibly be attributed to the work of IFAIM's team with 
the family. There were clinically significant changes, and the case was closed at the child protection services. At the end of intervention the parents were more capable of meeting the child's needs and positive development. They are also stronger and more confident in the future, relying not only a priori love and hope but also on their joint recent achievements and celebrated successes. At the end of intervention, they knew where to look for help when needed but also how to make use of their strengths. Intervention opened a door for them to continue to learn and grow. As they said, "it is easier to do when you have someone by your side and you can learn together."

This case study does not allow us to infer about IFAIM's efficacy. However, it does offer promising evidence that justifies future investigations with more controlled designs and progress research studies (Pinsof \& Wynne, 2000).

\section{ACKNOWLEDGMENTS}

Supported by a doctoral scholarship (SFRH/BD/39912/2007) attributed to the first author by the Foundation for Science and Technology, Portugal. The first author thanks the ASAS organization in Santo Tirso, Portugal, for making available the team of the Center for Family Support and Parental Counseling and providing the logistics to implement IFAIM for this case study.

\section{REFERENCES}

Barker, C. Pistrang, N., \& Elliot, R. (2002). Research methods in clinical psychology. An introduction for students and practitioners (2nd ed.). West Sussex, UK: John Wiley \& Sons.

Barnett, M. A. (2008). Economic disadvantage in complex family systems: Expansion of family stress models. Clinical Child and Family Psychology Review, 11, $145-161$.

Bell, S., \& Eyberg, S.M. (2002). Parent-child interaction therapy. In L. VandeCreek, S. Knapp, \& T.L. Jackson (Eds.), Innovations in clinical practice: A source book (Vol. 20, pp. 57-74). Sarasota, FL: Professional Resource Press.

Benzies, K., \& Mychasiuk, R. (2009). Fostering family resiliency: A review of the key protective factors. Child \& Family Social Work, 14, 103-114.

Berg, I. K., \& Kelly, S. (2000). Building solutions in child protective services. New York, NY: W. W: Norton \& Company.

Boyd-Franklin, N., \& Bry, B. H. (2000). Reaching out in family therapy: Home-based, school and community interventions. New York, NY: The Guilford Press.

Campbell, A. (2008). Clinical significance in real world settings. Australian and New Zealand Journal of Family Therapy, 29, 107-110.

Colapinto, J. A. (1995). Dilution of family process in social services: Implications for treatment of neglectful families. Family Process, 34, 59-74. 
Early, T. J., \& GlenMaye, L. F. (2000). Valuing families: Social work practice with families from a strengths perspective. Social Work, 45, 118-130.

Elliot, R. (2002). Hermeneutic single-case efficacy design. Psychotherapy Research, $12,1-21$.

Henggeler, S.W., Schoenwald, S.K., Rowland, M.D., \& Cunningham, P.B. (2002). Serious emotional disturbance in children and adolescents: Multisystemic therapy. New York, NY: The Guilford Press.

Jacobson, N. S., \& Truax, P. (1991). Clinical significance: A statistical approach to defining meaningful change in psychotherapy research. Journal of Consulting and Clinical Psychology, 59, 12-19.

Madsen, W. C. (2007). Collaborative therapy with multi-stressed families (2nd ed.). New York, NY: The Guilford Press.

Melo, A. T. (2011). As forças dos profissionais e da família multidesafiada na proteção da criança: Um modelo de avaliação e de intervenção familiar integrada para os CAFAP [The strengths of the professionals and the multichallenged family in the protection of the child: An integrated family assessment and intervention model for the CAFAP]. Coimbra, Portugal: FPCEUC. Unpublished doctoral thesis.

Melo, A. T., \& Alarcão, M. (2011a). Integrated family assessment and intervention model: A collaborative approach to support multi-challenged families. Contemporary Family Therapy, 33, 400-416.

Melo, A. T., \& Alarcão, M. (2011b). Capacidade parental e familiar em situações de risco: grelhas para avaliações compreensivas [Parental and family capacity in risk situations: grids for comprehensive assessments]. Manuscript submitted for publication.

Melo, A. T., \& Alarcão, M. (2011c). Avaliação de processos de resiliência familiar: Validade e fidelidade do Questionário de Forças Familiares [Assessment of family resilience processes: Validity and reliability of the Family Strengths Questionnaire]. Mosaico, 48, 34-41.

Melo, A. T., \& Alarcão, M. (2011d). Estudo preliminar das propriedades psicométricas de uma versão portuguesa do Multidimensional Neglectful Behavior ScaleParent Report [Preliminary study of the psychometric properties of a Portuguese version of the Multidimensional Neglectful Behavior Scale-Parent Report]. In M. M. Calheiros, M. Garrido, \& M. S. Santos (Eds.), Crianças em risco e perigo: contextos, investigação e intervenção (Vol. 1, pp. 81-98). Lisboa: Ślabo.

Minuchin, P., Colapinto, J., \& Minuchin, S. (2007). Working with families of the poor (2nd ed.). New York, NY: The Guilford Press.

Patterson, J. M. (2002). Integrating family resilience and family stress theory. Journal of Marriage and Family, 64, 349-360.

Pinsof, W., \& Wynne, L. C. (2000). Toward progress research: Closing the gap between family therapy practice and research. Journal of Marital and Family Therapy, 26, 1-8.

Scaramella, L. V., Neppl, T. K., Ontai, L. L., \& Conger, R. D. (2008). Consequences of socioeconomic disadvantage across three generations: Parenting behavior and externalizing problems. Journal of Family Psychology, 22, 725-733.

Sharlin, S. A., \& Shamai, M. (2000). Therapeutic intervention with poor, unorganized families. From distress to hope. New York, NY: The Haworth Clinical Practice Press. 
Wadsworth, M. E., \& Santiago, C. D. (2008). Risk and resiliency processes in ethnically diverse families in poverty. Journal of Family Psychology, 22, 399-410.

Walsh, F. (2006). Strengthening family resilience (2nd ed.). New York, NY: The Guilford Press.

White, M. (2007). Maps of narrative practice. New York, NY: W. W. Norton \& Company.

White, M., \& Epston, D. (1990). Narrative means to therapeutic ends. New York, NY: Norton.

Yin, R. K. (2009). Case study research. Design and methods (4th ed.). Thousand Oaks, CA: Sage. 